\title{
Renal Gluconeogenesis in Acidosis, Alkalosis, and Potassium Deficiency: Its Possible Role in Regulation of Renal Ammonia Production *
}

\author{
A. David Goodman $\nmid \nmid$ Robert E. Fuisz, $\$$ and George F. Cahill, Jr. $\S$ \\ (From the Elliott Joslin Research Laboratory, the Department of Medicine, Harvard Medical \\ School, the Peter Bent Brigham Hospital, and the Diabetes Foundation, Inc., Boston, \\ Mass., and the Subdepartment of Endocrinology and Metabolism, Department \\ of Medicine, Albany Medical College, Albany, N. Y.)
}

In man, dog, and rat the induction of metabolic acidosis leads to an increase in renal production and excretion of ammonia (2-4) that appears to derive primarily from glutamine (4-6). Studies of the renal cortex of the acidotic rat reveal an increase in the activity of glutaminase I, the enzyme that deamidates glutamine to glutamate (Figure 1 ), and it is assumed that this may contribute to the increase in ammoniagenesis from glutamine (2).

The mechanism by which acidosis evokes an increase in renal glutaminase I activity in the rat is not known. If acidosis directly stimulates the synthesis or activation of glutaminase $I$ it would be expected that the intracellular concentration of glutamate would be increased. Actually, the glutamate content of the renal cortex of acidotic rats is decreased $(7,8)$.

The concurrence in acidotic rats of decreased renal glutamate concentration and increased renal glutaminase I activity is of much interest. In a variety of biologic systems there exists a negative feedback between the intracellular concentration of an immediate or distant product of an enzymatic

\footnotetext{
* Submitted for publication August 5, 1965; accepted December 27, 1965.

Presented in part before the Eastern Section of the American Federation for Clinical Research, December 1964, and published in abstract form (1).

Supported in part by U. S. Public Health Service grants T1 AM 5077-09, AM 09584-01, and AM 09232-01, and the Hartford Foundation.

† This work was done in part during tenure as a Clinical Trainee in Endocrinology, National Institutes of Health. Present address: Albany Medical College, Albany, N. Y.

$\ddagger$ Special Fellow, National Institutes of Health.

§ Investigator, Howard Hughes Medical Institute.

Address requests for reprints to Dr. George F. Cahill, Jr., 170 Pilgrim Rd., Boston, Mass. 02215.
}

reaction, and either the rate of synthesis of the enzyme or the specific activity of the enzyme (9). It has been suggested that such a relationship may exist between glutamate and renal glutaminase I, and that the reduction in renal glutamate concentration in acidosis either stimulates the synthesis or enhances the specific activity of glutaminase I $(7,8)$.

As the fall in cortical glutamate content in acidosis may play a crucial role in the increase in renal ammoniagenesis, the mechanism of this fall is of interest. Renal cortex is known to have a remarkable capacity to produce glucose from glutamate and its products (10), and hence the possibility has been investigated that acidosis may decrease cortical glutamate by accelerating its conversion to glucose. In the studies to be described, it was found that renal cortical slices taken from rats with metabolic acidosis have an increased capacity to convert glutamate and $\boldsymbol{\alpha}$-ketoglutarate $(\alpha-K G)$ to glucose, and that in alkali-fed rats the cortical gluconeogenic capacity is decreased. Since renal glutaminase I and urinary ammonium excretion are known to be increased in potassium deficiency $(11,12)$, it was of interest to find that cortical tissue from potassium-depleted rats has an increased ability to convert glutamate and $\alpha$-KG to glucose.

These findings are consistent with the hypothesis that in metabolic acidosis and potassium depletion, the increase in cortical glutaminase I and ammonia production is mediated by a decrease in intracellular glutamate due to an increase in the rate of conversion of glutamate to glucose. Furthermore, the increased renal glutamine transaminase activity in acidotic rats and in potassium deficient rats (12) may result from a decrease in $\alpha-\mathrm{KG}$ - the secondary product of the transaminase 


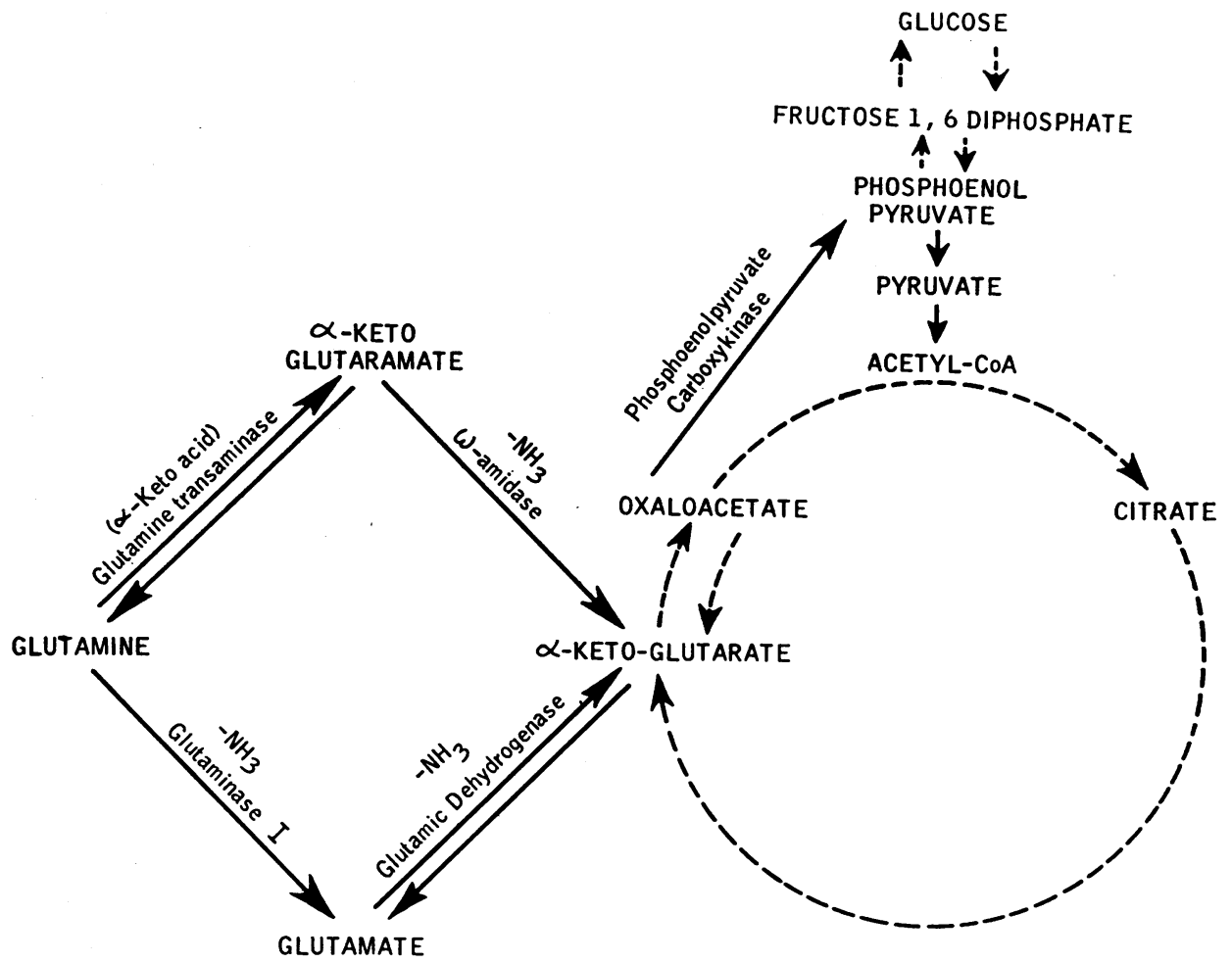

Fig. 1. Schematic diagram of Relation of Renal GLUTAMine MEtabolism to GLUCONEOGENESIS.

reaction-as a consequence of the enhanced conversion of $\alpha-\mathrm{KG}$ to glucose.

\section{Methods}

Sprague-Dawley male rats ${ }^{1}$ weighing 250 to $350 \mathrm{~g}$ were used in all experiments. For experiments requiring adrenalectomized rats, bilateral adrenalectomy was performed under ether anesthesia 4 days before initiation of the experimental protocol.

Acid-feeding protocol. A group of rats was deprived of solid food at the start of the experiment and given isotonic saline ad libitum. Half of the group were tube fed twice daily $10 \mathrm{ml}$ of a $20 \%$ dextrose solution containing $300 \mathrm{mM} \mathrm{NH} 4 \mathrm{Cl}$. The other half were tube fed in the same manner a $20 \%$ dextrose solution devoid of $\mathrm{NH}_{4} \mathrm{Cl}$. After two days of tube feeding the animals were sacrificed, and the gluconeogenic capacity of their renal cortical tissue was determined in a manner to be described.

To eliminate adrenal glucocorticoid secretion as a variable, we applied a similar protocol to a group of adrenalectomized rats. The feeding solutions were modified in that half of the rats received a $20 \%$ dextrose solution containing $130 \mathrm{mM} \mathrm{NH}{ }_{4} \mathrm{Cl}$, whereas the other half received the same solution devoid of $\mathrm{NH}_{4} \mathrm{Cl}$. At the time of sacrifice, blood was collected from some of these

\footnotetext{
1 Holtzman Laboratories, Madison, Wis.
}

rats by decapitation, and the serum $\mathrm{CO}_{2}$ content was found to be $17.2 \pm 1.5$ mmoles per $L(n=5)$ in the $\mathrm{NH}_{4} \mathrm{Cl}$-fed group, and $25.1 \pm 0.8$ mmoles per $\mathrm{L}(\mathrm{n}=4)$ in the control group.

To dissociate the acidifying effect of $\mathrm{NH}_{4} \mathrm{Cl}$ administration from the effect of $\mathrm{NH}_{4} \mathrm{Cl}$ per se, we made a group of adrenalectomized rats acidotic by tube feeding a $20 \%$ dextrose solution containing $150 \mathrm{mM} \mathrm{NH}_{4} \mathrm{Cl}$ and $150 \mathrm{mM} \mathrm{NaCl}$, whereas the control group received a $20 \%$ dextrose solution containing $150 \mathrm{mM} \mathrm{NH}_{4} \mathrm{Cl}$ and $150 \mathrm{mM} \mathrm{NaHCO}$.

To determine whether the administration of $\mathrm{NH}_{4} \mathrm{Cl}$ would affect the renal gluconeogenic capacity in as little as 12 hours, we performed the following study. Half of a group of adrenalectomized animals were tube fed $10 \mathrm{ml}$ of a $20 \%$ dextrose solution containing $150 \mathrm{mM}$ $\mathrm{NaCl}$ and $150 \mathrm{mM} \mathrm{NH}{ }_{4} \mathrm{Cl}$, and half were tube fed the same volume of a $20 \%$ dextrose solution containing 150 $\mathrm{mM} \mathrm{NaCl}$ but devoid of $\mathrm{NH}_{4} \mathrm{Cl}$. The animals were sacrificed 12 hours after the single feeding for studies of renal gluconeogenesis. In another experiment, the same protocol was followed except that the animals were sacrificed 6 hours after the feeding.

Alkali-feeding protocol. A group of rats was deprived of solid food at the start of the experiment. Half were tube fed twice daily $10 \mathrm{ml}$ of a $20 \%$ dextrose solution containing $450 \mathrm{mM} \mathrm{NaHCO}$ and allowed to drink ad libitum a solution containing $75 \mathrm{mM} \mathrm{NaHCO}$ and $75 \mathrm{mM}$ 
$\mathrm{NaCl}$. The other half were tube fed a $20 \%$ dextrose solution containing $450 \mathrm{mM} \mathrm{NaCl}$ and given isotonic saline ad libitum. After 2 days of tube feeding the animals were sacrificed and studies of renal gluconeogenesis were performed.

A similar protocol was applied to a group of adrenalectomized rats. The tube-feeding solutions were modified, in that half of the animals received a $20 \%$ dextrose solution containing $300 \mathrm{mM} \mathrm{NaHCO}$, whereas the other half received a $20 \%$ dextrose solution containing $300 \mathrm{mM}$ $\mathrm{NaCl}$.

Potassium depletion protocol. In studying the effect of potassium deficiency on renal gluconeogenesis, a protocol for producing potassium depletion was employed which ensured that at the end of the study both potassium-depleted and control animals would have had identical nutritional intakes. This was deemed important because alteration in carbohydrate intake is known to have a profound effect on renal glucose production (10).

A group of rats was placed on a low potassium diet. ${ }^{2}$ Isotonic saline was allowed ad libitum from the initiation of the synthetic diet until the time of sacrifice. During the first 9 days the animals were given daily subcutaneous injections of $1 \mathrm{mg}$ of deoxycorticosterone acetate in $0.4 \mathrm{ml}$ sesame oil. On the twelfth day they were deprived of the synthetic diet, and half were tube fed twice daily $10 \mathrm{ml}$ of a $20 \%$ dextrose solution containing $200 \mathrm{mM} \mathrm{KCl}$, whereas the other half were fed in the same manner a $20 \%$ dextrose solution devoid of $\mathrm{KCl}$. After 3 days of tube feeding, both the potassium-repleted and the potassium-depleted rats were sacrificed, and renal gluconeogenesis was studied.

A similar protocol was employed in a second study, with the modification that on the ninth day of the study all of the rats were bilaterally adrenalectomized under ether anesthesia.

In vitro studies of renal cortical gluconeogenic capacity. On completion of the various tube-feeding regimens, the rats were rapidly decapitated, the kidneys removed, and renal cortical slices made with a Stadie-Riggs microtome (13). Several 150 - to $200-\mathrm{mg}$ portions of sliced cortex from each animal were rinsed in isotonic saline at room temperature for a few minutes. One portion of slices from each animal was placed in a $50-\mathrm{ml}$ flask containing $10 \mathrm{ml}$ of modified Krebs-Ringer medium without added substrate, and the other portions were put in $50-\mathrm{ml}$ flasks containing $10 \mathrm{ml}$ of the same medium to which individual gluconeogenic substrates had been added in a $10 \mathrm{mM}$ concentration. The electrolyte composition of the substrate-free medium was $\mathrm{Na}, 145 \mathrm{mEq} ; \mathrm{K}, 4.5 \mathrm{mEq}$; $\mathrm{Ca}, 2.6 \mathrm{mEq} ; \mathrm{Mg}, 1.2 \mathrm{mEq} ; \mathrm{Cl}, 126 \mathrm{mEq} ; \mathrm{HCO}_{3}, 24$ $\mathrm{mEq} ; \mathrm{H}_{2} \mathrm{PO}_{4}, 1.2$ mmoles per $\mathrm{L}$; and $\mathrm{SO}_{4}, 1.2 \mathrm{mEq}$; it was equilibrated with $95 \% \mathrm{O}_{2}-5 \% \quad \mathrm{CO}_{2}$ before use and the resultant $\mathrm{pH}$ was 7.35 to 7.45 . Glutamic acid was added as monosodium glutamate, and $\alpha$-ketoglutaric and oxaloacetic acids were modified before addition to the

2 "Low potassium and sodium diet" of Nutritional Biochemicals Corp., Cleveland, Ohio, to which $\mathrm{NaCl}, 170$ mmoles per $\mathrm{kg}$ of diet, was added. media by titrating solutions of these acids to $\mathrm{pH} 7.40$ with $\mathrm{NaHCO}_{3}$ (the $\mathrm{pH}$ determinations being made after elimination of $\mathrm{H}_{2} \mathrm{CO}_{3}$ by bubbling with nitrogen). After flushing of the gas phase of the flasks with $95 \% \mathrm{O}_{2}-5 \%$ $\mathrm{CO}_{2}$, the flasks were incubated for 90 minutes at $37^{\circ} \mathrm{C}$ in an Eberbach metabolic shaker at 100 oscillations per minute.

After incubation, the tissue and media were separated by centrifugation, and the tissue was dried to constant weight by heating at $95^{\circ} \mathrm{C}$ for 24 hours. The media were deproteinized by the zinc sulfate-barium hydroxide method of Nelson (14), and glucose concentrations determined by the glucose oxidase technique (15). Glucose production in each flask was calculated as micromoles glucose produced per gram dry weight of tissue in 90 minutes. The production of glucose from a particular substrate was calculated for each animal by subtracting the glucose production of the animal's cortical slices incubated in substrate free medium from the glucose produced by its slices incubated in the presence of the substrate.

Changes in the glycogen content of the slices during incubation were not taken into account in the determination of glucose production. In preliminary studies cortical glycogen was determined by the method of Good, Kramer, and Somogyi (16), with the modification that the glucose derived from the glycogen was measured by the glucose oxidase technique (15). It was found that the glycogen content of the slices was very small (less than $2.5 \mu$ moles per $\mathrm{g}$ dry $\mathrm{wt}$ ) immediately before incubation, and that it was not significantly different at the end of incubation in either media with substrate or media without substrate.

Changes in the glucose content of the slices during incubation were also not taken into account. In preliminary studies cortical glucose was determined by homogenizing slices of cortex in $2 \%$ perchloric acid and measuring the glucose in the supernatant by the glucose oxidase technique (15). It was found that the glucose content of the slices was extremely small (less than $0.5 \mu$ mole per $g$ dry wt) immediately before incubation, and that it was not significantly altered after incubation in either media with substrate or media without substrate.

TABLE I

Effect of $\mathrm{NH}_{4} \mathrm{Cl}$ feeding of normal rats on the gluconecgenic capacity of renal cortex in vitro*

\begin{tabular}{|c|c|c|c|c|}
\hline \multirow[b]{2}{*}{ Substrate† } & \multicolumn{2}{|c|}{ Glucose production } & \multirow{2}{*}{$\begin{array}{l}\text { Per cent } \\
\text { change }\end{array}$} & \multirow[b]{2}{*}{$1)$} \\
\hline & Control & $\mathrm{NH}_{4} \mathrm{Cl}$-fed & & \\
\hline & \multicolumn{2}{|c|}{$\begin{array}{c}\mu m o l e s / g \text { dry } w t / 90 \\
\text { minutes } \pm S D\end{array}$} & & \\
\hline None & $19 \pm 3$ & $23 \pm 3$ & +21 & $<0.05$ \\
\hline Glutamine & $89 \pm 16$ & $156 \pm 23$ & +75 & $<0.001$ \\
\hline Glutamate & $91 \pm 18$ & $140 \pm 35$ & +54 & $<0.001$ \\
\hline$\alpha-K G$ & $133 \pm 22$ & $219 \pm 33$ & +65 & $<0.001$ \\
\hline
\end{tabular}

* Renal cortex of seven $\mathrm{NH}_{4} \mathrm{Cl}$-fed and seven control-fed animals was studied.

$\dagger$ Concentration $=10$ mmoles per L. $\alpha-\mathrm{KG}=\alpha$-ketoglutarate. 
TABLE II

Effect of $\mathrm{NH}_{4} \mathrm{Cl}$ feeding of adrenalectomized rats on the gluconeogenic capacity of renal cortex in vitro*

\begin{tabular}{|c|c|c|c|c|}
\hline \multirow[b]{2}{*}{ Substrate† } & \multicolumn{2}{|c|}{ Glucose production } & \multirow{2}{*}{$\begin{array}{c}\text { Per cent } \\
\text { change }\end{array}$} & \multirow[b]{2}{*}{ p } \\
\hline & Control & $\mathrm{NH}_{4} \mathrm{Cl}$-fed & & \\
\hline & \multicolumn{2}{|c|}{$\begin{array}{c}\mu m o l e s / g \text { dry wt/90 } \\
\text { minutes } \pm \stackrel{S D}{ }\end{array}$} & & \\
\hline None & $18 \pm 5$ & $24 \pm 8$ & +33 & $>0.05$ \\
\hline Glutamine & $104 \pm 18$ & $205 \pm 27$ & +96 & $<0.001$ \\
\hline Glutamate & $119 \pm 32$ & $188 \pm 31$ & +58 & $<0.001$ \\
\hline$\alpha-K G$ & $175 \pm 39$ & $289 \pm 50$ & +65 & $<0.001$ \\
\hline
\end{tabular}

* Renal cortex of seven $\mathrm{NH}_{4} \mathrm{Cl}$-fed and seven control-fed animals was studied.

+ Concentration $=10$ mmoles per $\mathrm{L}$.

\section{Results}

Acid-feeding studies. Renal cortical slices from normal rats fed $\mathrm{NH}_{4} \mathrm{Cl}$ for 2 days produced significantly more glucose from glutamine, glutamate, and $\alpha-K G$ than did slices from normal rats not fed $\mathrm{NH}_{4} \mathrm{Cl}$ (Table I). Slices from adrenalectomized rats fed $\mathrm{NH}_{4} \mathrm{Cl}$ for 2 days also had an increased capacity to produce glucose from these substrates (Table II). In similar studies of renal cortex from $\mathrm{NH}_{4} \mathrm{Cl}$-fed adrenalectomized rats, glucose production from oxalacetate increased, but there was no significant increase in glucose production from glycerol or fructose (Table III).

Cortical slices from a large group of normal rats fed $\mathrm{NH}_{4} \mathrm{Cl}$ for 2 days were compared with slice's from an equal number of normal rats that had not received $\mathrm{NH}_{4} \mathrm{Cl}$, with regard to their capacity for glucose production when incubated in the absence of exogenous substrate. In 27 animals fed $\mathrm{NH}_{4} \mathrm{Cl}$, mean cortical glucose production was $24 \pm 6$ $\mu$ moles per $\mathrm{g}$ dry wt tissue per 90 minutes, whereas in 27 control-fed animals it was $18 \pm 4$ ( $p<$

TABLE III

Effect of $\mathrm{NH}_{4} \mathrm{Cl}$ feeding of adrenalectomized rats on the capacity of the renal cortex to produce glucose from oxalacetate, fructose, and glycerol in vitro*

\begin{tabular}{|c|c|c|c|c|}
\hline \multirow[b]{2}{*}{ Substrate† } & \multicolumn{2}{|c|}{ Glucose production } & \multirow{2}{*}{$\begin{array}{l}\text { Per cent } \\
\text { change }\end{array}$} & \multirow[b]{2}{*}{$\mathbf{p}$} \\
\hline & Control & $\mathrm{NH}_{4} \mathrm{Cl}$-fed & & \\
\hline & \multicolumn{2}{|c|}{$\begin{array}{c}\mu m o l e s / g \text { dry wt/90 } \\
\text { minutes } \pm S D\end{array}$} & & \\
\hline Oxalacetate & $95 \pm 14$ & $172 \pm 25$ & +81 & $<0.001$ \\
\hline Fructose & $425 \pm 70$ & $429 \pm 29$ & +1 & $>0.10$ \\
\hline Glycerol & $53 \pm 6$ & $50 \pm 13$ & -6 & $>0.10$ \\
\hline
\end{tabular}

* Renal cortex of seven $\mathrm{NH}_{4} \mathrm{Cl}$-fed and seven control-fed animals was studied.

$\dagger$ Concentration $=10$ mmoles per $L$.
TABLE IV

A comparison of the effect of $\mathrm{NH}_{4} \mathrm{Cl}-\mathrm{NaHCO}$ feeding and of $\mathrm{NH}_{4} \mathrm{Cl}$ - $\mathrm{NaCl}$ feeding in adrenalectomized animals on the gluconeogenic capacity of renal cortex in vitro*

\begin{tabular}{|c|c|c|c|c|}
\hline \multirow[b]{2}{*}{ Substrate $†$} & \multicolumn{2}{|c|}{ Glucose production } & \multirow[b]{2}{*}{$\begin{array}{l}\text { Per cent } \\
\text { change }\end{array}$} & \multirow[b]{2}{*}{ p } \\
\hline & $\begin{array}{c}\mathrm{NH}_{4} \mathrm{Cl}- \\
\mathrm{NaHCO}_{3} \text {-fed }\end{array}$ & $\begin{array}{l}\mathrm{NH}_{4} \mathrm{Cl}- \\
\mathrm{NaCl}-\text { fed }\end{array}$ & & \\
\hline & \multicolumn{2}{|c|}{ 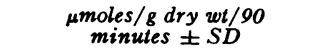 } & & \\
\hline None & $16 \pm 4$ & $24 \pm 12$ & +50 & $<0.01$ \\
\hline Glutamine & $102 \pm 14$ & $149 \pm 28$ & +46 & $<0.001$ \\
\hline Glutamate & $97 \pm 27$ & $140 \pm 17$ & +44 & $<0.001$ \\
\hline$\alpha-\mathrm{KG}$ & $125 \pm 20$ & $161 \pm 26$ & +29 & $<0.01$ \\
\hline
\end{tabular}

* Renal cortex of nine rats fed $\mathrm{NH}_{4} \mathrm{Cl}-\mathrm{NaHCO}_{3}$ and nine fed $\mathrm{NH}_{4} \mathrm{Cl}$ $\mathrm{NaCl}$ was studied.

$\dagger$ Concentration $=10$ mmoles per $\mathrm{L}$.

0.001 ). In a similar study in adrenalectomized rats, mean cortical glucose production in 44 $\mathrm{NH}_{4} \mathrm{Cl}$-fed animals was $20 \pm 5$, whereas in 46 control-fed animals it was $16 \pm 5(p<0.001)$.

Renal cortex from 13 adrenalectomized rats that were sacrificed 12 hours after a single feeding of 1.5 mmoles $\mathrm{NH}_{4} \mathrm{Cl}$ was found to produce $37 \%$ more glucose from glutamine $(\mathrm{p}<0.01)$ and $23 \%$ more glucose from oxalacetate $(\mathrm{p}<0.01)$ than did cortex from an equal number of control rats; gluconeogenesis from other substrates was not studied. No significant increase in gluconeogenesis from glutamine and oxalacetate was observable when adrenalectomized animals were sacrificed 6 hours after a single feeding of 1.5 mmoles $\mathrm{NH}_{4} \mathrm{Cl}$.

Renal cortex from adrenalectomized rats that were fed $\mathrm{NH}_{4} \mathrm{Cl}$ and an equimolar amount of $\mathrm{NaCl}$ for 2 days was found to produce more glucose from glutamine, glutamate, and $\alpha-\mathrm{KG}$ than did cortex from adrenalectomized rats fed the same amount of $\mathrm{NH}_{4} \mathrm{Cl}$ and an equimolar amount of $\mathrm{NaHCO}_{3}$ (Table IV).

TABLE V

Effect of $\mathrm{NaHCO}_{3}$ feeding of normal rats on the gluconeogenic capacity of renal cortex in vitro*

\begin{tabular}{|c|c|c|c|c|}
\hline \multirow[b]{2}{*}{ Substrate† } & \multicolumn{2}{|c|}{ Glucose production } & \multirow{2}{*}{$\begin{array}{l}\text { Per cent } \\
\text { change }\end{array}$} & \multirow[b]{2}{*}{ p } \\
\hline & Control & $\mathrm{NaHCO}_{2}$-fed & & \\
\hline & \multicolumn{2}{|c|}{$\begin{array}{c}\mu \text { moles } / g \text { dry } w t / 90 \\
\text { minutes } \pm S D\end{array}$} & & \\
\hline None & $19 \pm 2$ & $19 \pm 3$ & $\mathbf{0}$ & \\
\hline Glutamine & $74 \pm 11$ & $45 \pm 21$ & -39 & $<0.02$ \\
\hline Glutamate & $66 \pm 13$ & $36 \pm 17$ & -45 & $<0.01$ \\
\hline$\alpha-\mathbf{K G}$ & $98 \pm 39$ & $55 \pm 15$ & -44 & $<0.02$ \\
\hline
\end{tabular}

* Renal cortex of seven $\mathrm{NaHCO}_{3}$-fed and seven control-fed animals was studied.

+ Concentration $=10$ mmoles per $L$. 
TABLE VI

Effect of $\mathrm{NaHCO}_{3}$ feeding of adrenalectomized rats on the gluconeogenic capacity of renal cortex in vitro*

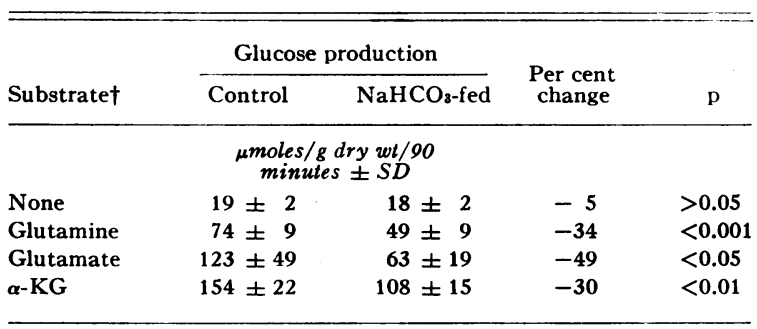

* Renal cortex of five $\mathrm{NaHCO}_{3}$-fed and seven control-fed animals was studied.

+ Concentration $=10$ mmoles per $\mathrm{L}$.

Alkali-feeding studies. Renal cortical slices from normal rats fed $\mathrm{NaHCO}_{3}$ for 2 days produced significantly less glucose from glutamine, glutamate, and $\alpha-\mathrm{KG}$ than did slices from normal rats not fed $\mathrm{NaHCO}_{3}$ (Table V). Cortex from adrenalectomized animals that had been fed $\mathrm{NaHCO}_{3}$ for 2 days was also found to have a decreased capacity to produce glucose from these substrates (Table VI).

Potassium deficiency studies. Renal cortex from normal rats that were depleted of potassium produced significantly more glucose from glutamine, glutamate, and $\alpha$-KG than did cortex from potassium-repleted normal rats (Table VII). Cortex from potassium deficient adrenalectomized rats also produced more glucose from these substrates than did cortex from potassium-repleted adrenalectomized rats (Table VIII). In both normal and adrenalectomized animals, potassium deficiency significantly enhanced the capacity of cortex to produce glucose in the absence of exogenous substrate (Tables VII and VIII).

TABLE VII

Effect of potassium deficiency in normal rats on the gluconeogenic capacity of renal cortex in vitro*

\begin{tabular}{|c|c|c|c|c|}
\hline \multirow[b]{2}{*}{ Substrate† } & \multicolumn{2}{|c|}{ Glucose production } & \multirow{2}{*}{$\begin{array}{l}\text { Per cent } \\
\text { change }\end{array}$} & \multirow[b]{2}{*}{ 1) } \\
\hline & K-repleted & K-deficient & & \\
\hline & \multicolumn{2}{|c|}{$\begin{array}{l}\mu \text { moles } / g \text { dry wt/90 } \\
\text { minutes } \pm S D\end{array}$} & & \\
\hline None & $14 \pm 6$ & $22 \pm 7$ & +57 & $<0.01$ \\
\hline Glutamine & $87 \pm 28$ & $123 \pm 28$ & +41 & $<0.01$ \\
\hline Glutamate & $96 \pm 22$ & $128 \pm 30$ & +33 & $<0.01$ \\
\hline$\alpha-K G$ & $97 \pm 16$ & $127 \pm 22$ & +31 & $<0.001$ \\
\hline
\end{tabular}

* Renal cortex of 14 potassium deficient and 14 potassium-repleted animals was studied.

+ Concentration $=10$ mmoles per $\mathrm{L}$.
TABLE VIII

Effect of potassium deficiency in adrenalectomized rats on the gluconeogenic capacity of renal cortex in vitro*

\begin{tabular}{|c|c|c|c|c|}
\hline \multirow[b]{2}{*}{ Substrate† } & \multicolumn{2}{|c|}{ Glucose production } & \multirow{2}{*}{$\begin{array}{l}\text { Per cent } \\
\text { change }\end{array}$} & \multirow[b]{2}{*}{$\mathrm{p}$} \\
\hline & K-repleted & $\mathrm{K}$ deficient & & \\
\hline & \multicolumn{2}{|c|}{$\begin{array}{c}\mu m o l e s / g d r y w t / 90 \\
\text { minutes } \pm S D\end{array}$} & & \\
\hline None & $19 \pm 3$ & $25 \pm 4$ & +32 & $<0.001$ \\
\hline Glutamine & $78 \pm 17$ & $110 \pm 29$ & +41 & $<0.001$ \\
\hline Glutamate & $55 \pm 10$ & $101 \pm 26$ & +84 & $<0.001$ \\
\hline$\alpha-\mathrm{KG}$ & $121 \pm 30$ & $170 \pm 39$ & +40 & $<0.001$ \\
\hline
\end{tabular}

* Renal cortex of 23 potassium deficient and 23 potassium-repleted animals was studied.

+ Concentration $=10 \mathrm{mmoles}$ per $\mathrm{L}$.

\section{Discussion}

The present observations indicate that in rats the administration of $\mathrm{NH}_{4} \mathrm{Cl}$ causes an increase in the capacity of the renal cortex to produce glucose from appropriate exogenous substrate. This increase is not mediated by enhanced production of adrenal glucocorticoid hormone (17), as it is demonstrable in adrenalectomized animals. It appears to be due to the acidifying action of $\mathrm{NH}_{4} \mathrm{Cl}$ rather than to a direct effect of this substance on the gluconeogenic process, for animals receiving $\mathrm{NH}_{4} \mathrm{Cl}$ and an equimolar amount of $\mathrm{NaCl}$ had increased gluconeogenesis compared with animals receiving the same amount of $\mathrm{NH}_{4} \mathrm{Cl}$ and an equimolar amount of $\mathrm{NaHCO}_{3}$. Consistent with the observation that the administration of an acidifying agent stimulates gluconeogenesis was the observation that the administration of alkali, in the form of $\mathrm{NaHCO}_{3}$, suppresses gluconeogenesis.

Acidosis might enhance cortical production of glucose from gluconeogenic substrates, either by increasing transport of these substrates into the cell, or by directly stimulating the intracellular mechanism for converting them to glucose. The possibility that the intracellular gluconeogenic mechanism is stimulated directly is strongly favored by the observation that when cortex from $\mathrm{NH}_{4} \mathrm{Cl}$-fed rats was incubated in the absence of exogenous substrate, it produced more glucoseundoubtedly from intracellular metabolites-than did slices from control animals. The finding that in $\mathrm{NH}_{4} \mathrm{Cl}$-fed animals there is increased renal glucose production from oxalacetate, as well as from glutamine, glutamate, and $\alpha-\mathrm{KG}$, suggests that the primary stimulatory effect of acidosis on gluconeogenesis is on a rate-limiting step between oxalacetate and glucose (Figure 1). 
The effects of metabolic acidosis and alkalosis on cortical gluconeogenesis may well be due to a direct influence of the $\mathrm{pH}$ of extracellular fluid on the cortical gluconeogenic process. Consistent with this hypothesis is the finding that cortical slices incubated in Krebs-Ringer medium at $\mathrm{pH}$ $7.1\left[\mathrm{HCO}_{3}, 12 \mathrm{mEq}\right.$; and $\mathrm{CO}_{2}$ pressure $\left(\mathrm{PcO}_{2}\right)$, t0 $\mathrm{mm} \mathrm{Hg}$ ] produce more glucose from glucose precursors than do slices incubated at $\mathrm{pH} 7.4$ $\left(\mathrm{HCO}_{3}, 24 \mathrm{mEq} ; \mathrm{PCO}_{2}, 40 \mathrm{~mm} \mathrm{Hg}\right)$, and that slices incubated at $\mathrm{pH} 7.7\left(\mathrm{HCO}_{3}, 48 \mathrm{mEq} ; \mathrm{PCO}_{2}\right.$, $40 \mathrm{~mm} \mathrm{Hg}$ ) produce less glucose than do slices incubated at $\mathrm{pH} 7.4$ (18).

Increased cortical conversion of glutamate to glucose may be responsible for the decrease in cortical glutamate concentration in acidotic animals $(7,8)$. Goldstein and Copenhaver have hypothesized that a negative feedback exists between renal glutamate and the synthesis of glutaminase I (7), and it is relevant that such a relationship appears to exist between glutamate and glutaminase $I$ in rat retina (19). Furthermore, glutamate is an inhibitor of glutaminase I activity (20), and the concentration of glutamate in rat renal cortex is approximately that required for $50 \%$ inhibition (8); consequently, the decrease in cortical glutamate in acidosis might well result in an increased rate of deamidation of glutamine, even in the absence of an increase in the concentration of the enzyme. Accordingly, the observed increase in cortical conversion of glutamate to glucose after acid feeding may constitute the first of the series of biochemical events leading to increased ammonia production via the glutaminase I pathway.

In acidotic rats there is an increase in cortical glutamine transaminase activity (12), which presumably contributes to the increase in ammoniagenesis (Figure 1). In many biologic systems a decrease in the concentration of a distant product of an enzymic reaction stimulates an increase in the synthesis or in the specific activity of the enzyme (9); it is reasonable to hypothesize that a decrease in cortical $\alpha-K G$ (the secondary product of the glutamine transaminase reaction) consequent to increased conversion of $\alpha$-KG to glucose may be the cause of the increased glutamine transaminase activity in acidosis.

In potassium deficiency, as in metabolic acidosis, urinary ammonium excretion is elevated and the cortical activity of glutaminase I and glutamine transaminase is increased $(11,12)$. The finding of increased cortical gluconeogenic capacity in potassium-depleted rats supports the hypothesis that the rate of cortical gluconeogenesis may play an important role in the regulation of renal ammonia production.

Renal gluconeogenesis may be a significant factor in over-all metabolism of carbohydrate in the body, for in vivo production of glucose by the kidneys is considerable $(21,22)$. The observation that acidosis and potassium depletion enhance the capacity of kidney cortex to produce glucose in vitro suggests that in these states the renal production of glucose in vivo may be increased. This may contribute to the decreased glucose tolerance observed in both metabolic acidosis (23) and potassium deficiency (24).

It has been observed that metabolic alkalosis decreases renal consumption of $\alpha$-KG in vivo (25). This may be explained by the present finding that alkalosis decreased the capacity of the kidney to convert $\alpha$-KG to glucose, for the ability of the kidney to dissimilate $\alpha-\mathrm{KG}$ is probably contingent in part on its capacity to incorporate it into glucose.

The compounds of the citric acid cycle cannot be dissipated through the reactions of this cycle per se, for, although with each passage of an intermediate around the cycle two carbon atoms are removed as $\mathrm{CO}_{2}$, two other carbons are added as acetate. Consequently, the dissimilation of $\alpha-\mathrm{KG}$ in the body is probably dependent upon the fact that in some tissues the oxalacetate arising from this compound can "escape" the cycle by conversion to phosphoenolpyruvate (PEP) under the influence of PEP carboxykinase (26) (Figure 1). Consistent with this concept is the fact that the only tissues known to extract significant quantities of $\alpha$-KG from blood are those that contain PEP carboxykinase, namely kidney and liver $(26$, 27 ). The PEP formed in these organs from oxalacetate can either be converted to acetate and oxidized by the citric acid cycle, or converted to glucose, which can then be metabolized by glycolytic tissue such as muscle and brain. The renal conversion of $\alpha$-KG to glucose is probably considerable, since the renal uptake of oxygen is much less than would be expected if all the $\alpha$-KG extracted by the kidney were oxidized to $\mathrm{CO}_{2}$ and water (28). 


\section{Summary}

Renal cortical slices from rats fed $\mathrm{NH}_{4} \mathrm{Cl}$ have an increased capacity to produce glucose from glutamine, glutamate, and $\alpha$-ketoglutarate $(\alpha-K G)$, and slices from $\mathrm{NaHCO}_{3}$-fed rats have a decreased capacity to produce glucose from these substrates. Cortex from potassium-depleted rats manifests increased gluconeogenesis from these compounds. The stimulatory effect of acidosis and potassium depletion on renal gluconeogenic capacity can be demonstrated in adrenalectomized rats, and is therefore not mediated by increased adrenal glucocorticoid secretion.

The increased renal formation of glucose from glutamate and $\alpha-\mathrm{KG}$ in acidosis and potassium depletion is intimately related to the increase in renal ammonia production observed in these states. The hypothesis is presented that enhanced conversion of glutamate and $\alpha-\mathrm{KG}$ to glucose causes a decrease in the intracellular concentration of these metabolites, and that this decrease causes accelerated synthesis or activation of glutaminase I and glutamine transaminase, with a consequent increase in ammonia production from glutamine.

The present findings may be relevant to the diminished glucose tolerance in metabolic acidosis and potassium depletion and to the decrease in renal extraction of $\alpha-\mathrm{KG}$ in alkalosis.

\section{Acknowledgments}

We gratefully acknowledge the invaluable technical assistance of Miss Judith Flewelling of Boston and Miss Elizabeth Sheldon of Albany.

\section{References}

1. Goodman, A. D., R. E. Fuisz, and G. F. Cahill, Jr. Role of renal gluconeogenesis in regulation of renal ammonia production. Clin. Res. 1964, 12, 469.

2. Leonard, E., and J. Orloff. Regulation of ammonia excretion in the rat. Amer. J. Physiol. 1955, 182, 131.

3. Pitts, R., J. DeHaas, and J. Klein. Relation of renal amino and amide nitrogen extraction to ammonia production. Amer. J. Physiol. 1963, 204, 187.

4. Owen, E., and R. R. Robinson. Amino acid extraction and ammonia metabolism by the human kidney during the prolonged administration of ammonium chloride. J. clin. Invest. 1963, 42, 263.

5. Shalhoub, R., W. Webber, S. Glabman, M. CanessaFischer, J. Klein, J. DeHaas, and R. Pitts. Ex- traction of amino acids from and their addition to renal blood plasma. Amer. J. Physiol. 1963, 204, 181.

6. Davies, B. M. A., and J. Yudkin. Studies in biochemical adaptation. The origin of urinary ammonia as indicated by the effect of chronic acidosis and alkalosis on some renal enzymes in the rat. Biochem. J. 1952, 52, 407.

7. Goldstein, L., and J. H. Copenhaver, Jr. Relation of glutaminase I activity to glutamic acid concentration in the rat kidney. Amer. J. Physiol. 1960, 198, 227.

8. Goldstein, L., and J. M. Schooler. Relation of renal glutamate concentration to acid-base balance and urinary ammonia production. Fed. Proc. 1965, 24, 582.

9. Moyed, H. S., and H. E. Umbarger. Regulation of biosynthetic pathways. Physiol. Rev. 1962, 42, 444.

10. Krebs, H. A., D. A. H. Bennett, P. De Gasquet, T. Gascoyne, and T. Yoshida. Renal gluconeogenesis. The effect of diet on the gluconeogenic capacity of rat-kidney-cortex slices. Biochem. J. 1963, 86, 22.

11. Iacobellis, M., E. Muntwyler, and G. E. Griffin. Enzyme concentration changes in the kidneys of protein- and/or potassium-deficient rats. Amer. J. Physiol. 1954, 178, 477.

12. Goldstein, L. Relation of renal glutamine transaminase- $\omega$-amidase activity to ammonia excretion in the rat. Nature (Lond.) 1964, 201, 1229.

13. Stadie, W. C., and B. C. Riggs. Microtome for the preparation of tissue slices for metabolic studies of surviving tissues in vitro. J. biol. Chem. 1944, 154,687

14. Nelson, N. A photometric adaptation of the Somogyi method for the determination of glucose. J. biol. Chem. 1944, 153, 375.

15. Huggett, A. St. G., and D. A. Nixon. Use of glucose oxidase, peroxidase, and o-dianisidine in determination of blood and urinary glucose. Lancet 1957, 2, 368.

16. Good, C. A., H. Kramer, and M. Somogyi. The determination of glycogen. J. biol. Chem. 1933, 100, 485.

17. Landau, B. Gluconeogenesis and pyruvate metabolism in rat kidney, in vitro. Endocrinology 1960, 67, 744.

18. Fuisz, R. E., A. D. Goodman, D. E. Kamm, G. F. Cahill, Jr., and A. Marble. Metabolic implications of renal gluconeogenesis in rate control of ammonia synthesis (abstract). J. clin. Invest. 1965, 44, 1049.

19. Freedman, J., and V. Potts. Repression of glutaminase $I$ in the rat retina by administration of sodium-L-glutamate. Invest. Ophthal. 1963, 2, 252.

20. Klingman, J., and P. Handler. Partial purification and properties of renal glutaminase. J. biol. Chem. 1958, 232, 369. 
21. Dzúrik, R., B. Krajči-Lazáry, and T. R. Niederland. Glucose metabolism in rat kidney: influence of insulin and adrenaline. J. Physiol. (Lond.) 1963, 168, 782.

22. McCann, W., and J. R. Jude. The synthesis of glucose by the kidney. Bull. Johns Hopk. Hosp. 1958, 103, 77.

23. Mackler, B., H. Lichtenstein, and G. M. Guest. Effects of ammonium chloride acidosis on glucose tolerance in dogs. Amer. J. Physiol. 1952, 168, 126.

24. Sagild, U., V. Andersen, and P. G. Andreasen. Glucose tolerance and insulin responsiveness in ex- perimental potassium depletion. Acta med. scand. 1961, 169, 243.

25. Cohen, J. J., and E. Wittman. Renal utilization and excretion of $\alpha$-ketoglutarate in the dog: effect of alkalosis. Amer. J. Physiol. 1963, 204, 795.

26. Utter, M. F. The role of $\mathrm{CO}_{2}$ fixation in carbohydrate utilization and synthesis. Ann. N. Y. Acad. Sci. 1958, 72, 451.

27. Selleck, B. H., and J. J. Cohen. Specific localization of $\alpha$-ketoglutarate uptake to dog kidney and liver in vivo. Amer. J. Physiol. 1965, 208, 24.

28. Cohen, J. J. High respiratory quotient of dog kidney in vivo. Amer. J. Physiol. 1960, 199, 560. 